\title{
KONTRIBUSI PEKERJAAN SAMBILAN TERHADAP KESEJAHTERAAN NELAYAN PANCING ULUR DI DESA TATELI WERU KECAMATAN MANDOLANG KABUPATEN MINAHASA
}

\author{
Rendi Rondonuwu'; Victoria E.N. Manoppo²; Grace O. Tambani² \\ 1)Mahasiswa Fakultas Perikanan dan IImu Kelautan Universitas Sam Ratulangi Manado \\ 2)Staff Pengajar Fakultas Perikanan dan IImu Kelautan Universitas Sam Ratulangi Manado \\ Koresponden email : rondonuwurendi@yahoo.com
}

\begin{abstract}
The purpose of this study is 1) to analyze how the contribution of odd jobs to fishing fishermen's income is stretching in order to increase family income; 2 ) to assess how much the contribution of part-time work to fishing income is stretched in order to increase family income in Tateli Weru Village, Mandolang District, Minahasa Regency. The method used in this study is qualitative. Qualitative approach is a research procedure by producing descriptive data in the form of written or oral words from people and observed behavior. The population in this study was stretcher fishing in the village of Tateli Weru consisting of full fishermen, main side fishermen and additional side fishermen. The results of the study of respondents in the village of Tateli Weru showed that the fishing gear used was nets, fishing rods and charts as well as rain boats and outboard motors. Diversification of work for fishermen included 10 motorcycle taxi drivers, 3 farmers, 16 construction workers and 1 stall business. Per capita income as farm labor Rp.6,525,555 per year, construction workers, Rp.3,205,062, motorcycle taxi drivers Rp.4,400,000, and stall business Rp.13,200,000.
\end{abstract}

Key Words: Contributions, diversification, odd jobs, Tateli Weru

\begin{abstract}
Abstrak
Tujuan penelitian ini adalah 1) untuk menganalisis bagaimana kontribusi pekerjaan sambilan terhadap pendapatan nelayan pancing ulur dalam rangka meningkatkan pendapatan keluarga; 2) untuk mengkaji berapa besar kontribusi pekerjaan sambilan terhadap pendapatan nelayan pancing ulur dalam rangka meningkatkan pendapatan keluarga di Desa Tateli Weru Kecamatan Mandolang Kabupaten Minahasa. Metode yang digunakan dalam penelitian ini, yaitu kualitatif. Pendekatan kualitatif merupakan prosedur penelitian dengan menghasilkan data deskriptif yang berupa kata-kata tertulis atau lisan dari orang-orang dan perilaku yang diamati. Populasi dalam penelitian ini dalah nelayan pancing ulur yang berada di Desa Tateli Weru yang terdiri atas nelayan penuh, nelayan sambilan utama dan nelayan sambilan tambahan. Hasil penelitian terhadap responden di Desa Tateli Weru menunjukkan alat tangkap yang digunakan adalah jaring, pancing dan bagan serta perahu pelang dan motor tempel. Diversifikasi pekerjaan nelayan antara lain tukang ojek sebanyak 10 orang, petani sebanyak 3 orang, buruh bangunan sebanyak 16 orang dan usaha warung sebanyak 1 orang. Pendapatan per kapita sebagai buruh tani Rp.6.525.555 per tahun, buruh bangunan, Rp.3.205.062, tukang ojek Rp.4.400.000, dan usaha warung Rp.13.200.000.
\end{abstract}

Kata kunci: Kontribusi, diversifikasi, pekerjaan sambilan, Tateli Weru

\section{PENDAHULUAN}

Sektor kelautan dan perikanan menjadi salah satu program prioritas pembangunan daerah. Karena itu ini menjadi tujuan utama guna mewujudkan kedaulatan pangan dalam menunjang berbagai sektor pembangunan lainnya. harapan ini sangat realistis karena Sulawesi Utara (Sulut) memiliki potensi sumberdaya kemaritiman yang sangat besar. Perkembangan positif itu juga didukung pemerintah pusat sehingga Sulut semakin memfokuskan pembangunan sektor kelautan dan perikanan melalui pengelolaan sumberdaya perikanan budidaya, penguatan daya saing produk kelautan, perikanan dan pengelolaan ruang laut.

Provinsi Sulawesi Utara merupakan salah satu daerah yang memiliki nelayan yang cukup signifikan yaitu Desa Tateli Weru dengan sebagian penduduk bermata pencaharian sebagai nelayan berjumlah kurang lebih 100 orang. Mandolang merupakan sebuah Kecamatan di Kabupaten Minahasa, Provinsi Sulawesi Utara, memiliki 12 desa, tetapi hanya 6 desa saja yang termasuk desa pantai, yaitu: Kalasey, Tateli 1, Tateli 2, Tateli 3, Tateli Weru dan Koha. Di Kecamatan Mandolang ada juga nelayan yang dalam usahanya bersifat mandiri dan nelayan yang bersifat kelompok, baik 
dalam mandiri maupun kelompok mempunyai karakteristik yamg berbeda dari segi sosial dan ekonomi (Kantor Desa).

Berdasarkan ke 6 desa tersebut, maka yang menjadi tempat penelitian yaitu Tateli Weru, karena di Desa Tateli weru memiliki jumlah nelayan yang cukup banyak dan kelompok nelayan yang ada di Tateli Weru hingga saat ini masih aktif (Kantor Desa Tateli Weru).

Pekerjaan nelayan sangat bergantung pada keadaan cuaca, pada kondisi cuaca baik maka kegiatan melaut dapat dilaksanakan dengan mudah. Namun ketika cuaca berganti menjadi tidak bersahabat, maka kegiatan penangkapan ikan tidak dapat dilaksanakan. Faktor pembatas nelayan terhadap kondisi cuaca akan berdampak pada nelayan tidak dapat lagi melakukan aktivitas penangkapan ikan pada cuaca yang tidak baik. Hal ini menyebabkan nelayan tidak akan mendapatkan penghasilan. Kondisi ini perlu diatasi nelayan, jika tidak maka nelayan dan anggota keluarga akan mengalami kekurangan biaya dan bahkan kelaparan. Salah satu cara mengatasi faktor pembatas ini, yaitu diversivikasi usaha. Diversifikasi diartikan sebagai kegiatan atau tindakan untuk membuat sesuatu menjadi lebih beragam atau tidak terpaku pada satu jenis saja baik pada industri yang terkait (related) ataupun tidak terkait (unrelated) Montgomery (1994) dalam Vanarasi (2005).

\section{METODE PENELITIAN}

Metode yang digunakan dalam penelitian ini, yaitu kualitatif. Menurut Saryono (2010), penelitian kualitatif merupakan penelitian yang digunakan untuk menyelidiki, menemukan, menggambarkan dan menjelaskan kualitas atau keistimewaan dari pengaruh sosial yang tidak dapat dijelaskan, diukur atau digambarkan melalui pendekatan kuantitatif. Pada dasarnya penelitian kualitatif ini landasan teoritisnya bertumpu secara mendasar pada fenomenologi dan menggali makna penelitian.

Populasi dalam penelitian ini dalah nelayan pancing ulur yang berada di Desa Tateli Weru yang berjumlah kurang 110 orang. Nelayan yang berjumlah 110 orang ini terdiri atas nelayan penuh, nelayan sambilan utama dan nelayan sambilan tambahan. Untuk Penelitian ini disurvei jenis nelayan sambilan tambahan dengan menggunakan metode purposive sampling, sehingga akan diperoleh nelayan-nelayan yang memiliki pekerjaan sambilan dan pekerjaan utamanya sebagai nelayan. Melalui bantuan informan diperoleh data bahwa jumlah nelayan yang memiliki pekerjaan sambilan adalah 75 orang, dengan pekerjaan sambilan adalah buruh tani (3 orang), buruh bangunan (40 orang), tukang ojek (31 orang) dan usaha warung (1 orang).

Untuk penelitian ini jumlah yang akan diambil berjumlah 30 orang dengan rincian sebagai berikut (buruh tani 3 orang, buruh bangunan 16 orang, tukang ojek 10 orang dan usaha warung 1 orang). Kemudian data ini didata, dibahas, dihitung serta menjelaskan berapa kontribusi pekerjaan tambahan atau pekerjaan sambilan yang mereka lakukan dalam rangka menunjang ekonomi keluarga.

Adapun data penelitian bersumber dari data primer dan data sekunder. Data primer adalah data yang diperoleh melalui wawacara langsung, melalui pengisian kuisioner dan juga alat perekam (Sekaran, 2011). Data primer adalah data yang diperoleh secara langsung dari responden yang ada di Desa Tateli Weru melalui wawancara langsung, observasi dan alat perekam. 
Informan adalah orang yang berada pada lingkup penelitian artinya orang yang dapat memberikan informasi tentang situasi dan kondisi latar penelitian, jadi sebagai informan harus memiliki banyak pengalaman tentang masalah penelitian dan secara sukarela menjadi sumber informasi meskipun tidak secara formal mereka dapat memberikan pandangannya dari dalam tentang nilai-nilai, sikap, bangunan, proses dan kebudayaan yang menjadi latar penelitian setempat. Saat melakukan wawancara, penulis menentukan beberapa sumber atau informan yang dianggap paling representatif untuk menjawab pertanyaanpertanyaan berkenaan dengan fokus penelitian.

\section{HASIL DAN PEMBAHASAN Kontribusi Pekerjaan Sambilan}

Hasil yang saya catat dari DKP Provinsi Sulut bahwa tidak ada data tentang pendapatan nelayan baik dari tingkat provinsi maupun Dati II se Sulut. Namun menurut DKP Provinsi merek mengutip pada (Statistika, KKR 2017) bahwa jumlah nelayan di tahun 2017 berjumlah 179.231 orang sedangkan jumlah produksi TTC 200.860 ton ditahun 2017. Harga ikan JTC yang kami dapatkan dari DKP Provinsi yaitu rata-rata Rp7.500 per kg.sehingga bisa diprediksi perhitungan pendapatan setahun dari hasil perikanan laut yaitu $200.860 \times 1000$ $x \operatorname{Rp} 7.500=$ Rp. 1.506.450.000.000; selanjutnya pendapatan seorang nelayan di Sulut menjadi Rp1.506.450.000.000: $179.231=$ Rp8.405.000/tahun .

Hasil diatas menunjukkan bahwa ternyata pendapatan nelayan Tateli Weru bukan masalah tentang pendapatan walaupu lebih kecil dari pendapatan ratarata nelayan di Sulut sebab mereka merasa cukup karena ada pekerjaan sambilan dan di tinjau dari segi pengeluaran, justru mereka masih bisa menabung.

Adapun yang dimaksud dengan kontribusi pekerjaan sambilan yaitu berapa besar pendapatan nelayan yang berprofresi sebagai nelayan namun mempunyai pekerjaan sambilan sebagai buruh tani, buruh bangunan tukang ojek, dan usaha warung dapat dilihat pada Tabel 1, 2, 3 dan 4 berikut ini.

\section{Buruh Tani}

Kontribusi pekerjaan sambilan sebagai buruh tani dapat dilihat pada Tabel 1 berikut ini.

Tabel 1. Kontribusi Pendapatan Sambilan Sebagai Buruh Tani

\begin{tabular}{|c|l|r|r|r|r|c|}
\hline No & \multicolumn{1}{|c|}{$\begin{array}{c}\text { Nama Responden } \\
\text { Utama } \\
\text { (Rp) }\end{array}$} & $\begin{array}{c}\text { Pendapatan } \\
\text { Sambilan } \\
\text { (Rp) }\end{array}$ & $\begin{array}{c}\text { Pengeluaran } \\
\text { (Rp) }\end{array}$ & $\begin{array}{c}\text { Total } \\
\text { Pendapatan } \\
\text { (Rp) }\end{array}$ & \multicolumn{1}{c|}{$\begin{array}{c}\text { Persentase } \\
(\%)\end{array}$} \\
\hline 1 & Bernadus M. & $2,250,000$ & $1,700,000$ & 735,000 & $3,950,000$ & 43.04 \\
\hline 2 & Nardy & $2,500,000$ & $2,500,000$ & 660,000 & $5,000,000$ & 50.00 \\
\hline 3 & Markus Frans & $2,000,000$ & $2,000,000$ & 650,000 & $4,000,000$ & 50.00 \\
\hline \multicolumn{2}{|c|}{ Jumlah } & $6,750,000$ & $6,200,000$ & $2,045,000$ & $12,950,000$ & \\
\hline \multicolumn{2}{|c|}{ Rata-rata } & $2,250,000$ & $2,066,667$ & 681,667 & $4,316,667$ & 47.68 \\
\hline
\end{tabular}

Sumber: Hasil Pengolahan Data, 2019

Kontribusi pekerjaan sebagai buruh tani rata-rata sebesar $\mathrm{Rp} 2.066 .667$ $(47,68 \%)$ dengan total pendapatan ratarata sebesar $\operatorname{Rp} 4,316,667$, sehingga pekerjaan sambilan selain sebagai nelayan dapat memberikan kontribusi terhadap pendapatan untuk kelangsungan hidup keluarga nelayan yang bersangkutan. Dengan adanya pekerjaan sambilan sebagai buruh tani maka keadaan perekonomian keluarga menjadi semakin membaik. Dibandingkan dengan pendapatan nelayan di Sulut $\mathrm{Rp}$. 
8.405.000/tahun memang agak kecil tapi mereka merasa cukup.
Kontribusi pekerjaan sambilan sebagai buruh bangunan dapat dilihat pada Tabel 2 berikut ini.

\section{Buruh Bangunan}

Tabel 2. Kontribusi Pendapatan Sambilan Sebagai Buruh Bangunan

\begin{tabular}{|c|l|r|r|r|r|r|}
\hline No & \multicolumn{1}{|c|}{ Nama Responden } & $\begin{array}{c}\text { Pendapatan } \\
\text { Utama } \\
\text { (Rp) }\end{array}$ & $\begin{array}{c}\text { Pendapatan } \\
\text { Sambilan } \\
\text { (Rp) }\end{array}$ & $\begin{array}{c}\text { Pengeluaran } \\
\text { (Rp) }\end{array}$ & $\begin{array}{c}\text { Total } \\
\text { Pendapatan } \\
\text { (Rp) }\end{array}$ & $\begin{array}{c}\text { Persentasi } \\
(\%)\end{array}$ \\
\hline 1 & Noldy Petrus & $2,000,000$ & $2,000,000$ & 890,000 & $4,000,000$ & 50.00 \\
\hline 2 & Agustian M. & $2,700,000$ & $1,500,000$ & 820,000 & $4,200,000$ & 35.71 \\
\hline 3 & Antonius Rudon & $2,000,000$ & $1,700,000$ & 550,000 & $3,700,000$ & 45.95 \\
\hline 4 & Sarapil Maluku & $2,500,000$ & $1,500,000$ & 950,000 & $4,000,000$ & 37.50 \\
\hline 5 & Andreas Kanaitem & $2,400,000$ & $1,600,000$ & 895,000 & $4,000,000$ & 40.00 \\
\hline 6 & Albert Bagunan & $2,750,000$ & $1,750,000$ & 550,000 & $4,500,000$ & 38.89 \\
\hline 7 & Muris Magikehang & $2,500,000$ & $1,750,000$ & 700,000 & $4,250,000$ & 41.18 \\
\hline 8 & Obet Pegia & $2,500,000$ & $1,750,000$ & 950,000 & $4,250,000$ & 41.18 \\
\hline 9 & Yan Maarisit & $2,500,000$ & $1,800,000$ & 875,000 & $4,300,000$ & 41.86 \\
\hline 10 & David Bawotong & $2,400,000$ & $2,000,000$ & 900,000 & $4,400,000$ & 45.45 \\
\hline 11 & Peter Daud & $2,500,000$ & $1,500,000$ & 700,000 & $4,000,000$ & 37.50 \\
\hline 12 & Toni David & $2,600,000$ & $1,700,000$ & 900,000 & $4,300,000$ & 39.53 \\
\hline 13 & Marten Tobias & $2,000,000$ & $2,000,000$ & 825,000 & $4,000,000$ & 50.00 \\
\hline 14 & Julius Thomas & $2,750,000$ & $1,400,000$ & $1,100,000$ & $4,150,000$ & 33.73 \\
\hline 15 & Andreas Tatura & $2,500,000$ & $1,800,000$ & 975,000 & $4,300,000$ & 41.86 \\
\hline 16 & Paul Maarisit & $3,100,000$ & $1,500,000$ & 900,000 & $4,600,000$ & 32.61 \\
\hline
\end{tabular}

Sumber: Hasil Pengolahan Data, 2019

\section{Kontribusi pekerjaan sebagai} buruh bangunan rata-rata sebesar Rp1.703.125 (40,81\%) dengan total pendapatan rata-rata sebesar Rp4,184,375, sehingga pendapatan sambilan selain sebagai C nelayan memberikan kontribusi terhadap pendapatan keluarga nelayan dan pendapatan sebagai buruh bangunan sebagai pelengkap atau sebagai penopang atau juga bisa sebagai dana untuk ditabung. Dibandingkan dengan pendapatan nelayan di Sulut Rp8.405.000/tahun memang agak kecil tapi mereka merasa cukup.

\section{Tukang Ojek}

Kontribusi pekerjaan sambilan sebagai tukang ojek dapat dilihat pada Tabel 13 berikut ini.

Tabel 3. Kontribusi Pendapatan Sambilan Sebagai Tukang Ojek

\begin{tabular}{|c|c|c|c|c|c|c|}
\hline No & Nama Responden & $\begin{array}{c}\text { Pendapatan } \\
\text { Utama } \\
\text { (Rp) }\end{array}$ & $\begin{array}{c}\text { Pendapatan } \\
\text { Sambilan } \\
(\mathrm{Rp})\end{array}$ & $\begin{array}{l}\text { Pengeluaran } \\
\text { (Rp) }\end{array}$ & $\begin{array}{c}\text { Total } \\
\text { Pendapatan } \\
\text { (pRp) }\end{array}$ & $\begin{array}{c}\text { Persentase } \\
(\%)\end{array}$ \\
\hline 1 & Rommi Jacobus & $2,500,000$ & $1,500,000$ & 640,000 & $4,000,000$ & 37.50 \\
\hline 2 & Anton Alinaung & $2,500,000$ & $1,000,000$ & 700,000 & $3,500,000$ & 28.57 \\
\hline 3 & Joseph Lumiri & $2,700,000$ & $1,200,000$ & 950,000 & $3,900,000$ & 30.77 \\
\hline 4 & Bert Barao & $2,500,000$ & $1,500,000$ & $1,000,000$ & $4,000,000$ & 37.50 \\
\hline 5 & Gideon Sekeon & $2,600,000$ & $1,100,000$ & 875,000 & $3,700,000$ & 29.73 \\
\hline 6 & Martinus Salanggamo & $2,400,000$ & $1,000,000$ & 900,000 & $3,400,000$ & 29.41 \\
\hline 7 & Andre Magikehang & $2,500,000$ & $1,000,000$ & 900,000 & $3,500,000$ & 28.57 \\
\hline 8 & Yordan Frans & $2,500,000$ & $1,200,000$ & 750,000 & $3,700,000$ & 32.43 \\
\hline 9 & Stevanus Sasue & $2,300,000$ & $1,500,000$ & 850,000 & $3,800,000$ & 39.47 \\
\hline 10 & Juan Salele & $2,700,000$ & $1,400,000$ & 700,000 & $4,100,000$ & 34.15 \\
\hline & Jumlah & $25,200,000$ & $12,400,000$ & $8,265,000$ & $37,600,000$ & \\
\hline & Rata-rata & $2,520,000$ & $1,240,000$ & 826,500 & $3,760,000$ & 32.81 \\
\hline
\end{tabular}


Sumber: Hasil Pengolahan Data, 2019

Kontribusi pekerjaan sebagai tukang ojek rata-rata sebesar Rp1.240.000 $(32,81 \%)$ dengan total pendapatan ratarata sebesar Rp3.760.000, sehingga pekerjaan sambilan selain sebagai nelayan dapat memberikan kontribusi terhadap pendapatan untuk kelangsungan hidup keluarga nelayan yang bersangkutan. Adanya pekerjaan sambilan sebagai tukang ojek di saat tidak melalut merupakan hal yang menjadi harapan sebagai penopang ekonomi nelayan tersebut beserta keluarganya. Dibandingkan dengan pendapatan nelayan di Sulut Rp8.405.000/tahun memang agak kecil tapi mereka merasa cukup.

\section{Usaha Warung}

Kontribusi pekerjaan sambilan usaha warung dapat dilihat pada Tabel 4 berikut ini.

Tabel 4. Kontribusi Pendapatan Sambilan Usaha Warung

\begin{tabular}{|l|l|c|c|c|c|c|}
\hline No & Nama Responden & $\begin{array}{c}\text { Pendapatan } \\
\text { Utama } \\
(\mathrm{Rp})\end{array}$ & $\begin{array}{c}\text { Pendapatan } \\
\text { Sambilan } \\
(\mathrm{Rp})\end{array}$ & $\begin{array}{c}\text { Pengeluaran } \\
(\mathrm{Rp})\end{array}$ & $\begin{array}{c}\text { Total } \\
\text { Pendapatan } \\
(\mathrm{pRp})\end{array}$ & $\begin{array}{c}\text { Persentase } \\
(\%)\end{array}$ \\
\hline & Jansen Tuati & $2,500,000$ & $1,500,000$ & 700,000 & $4,000,000$ & $37.50 \%$ \\
\hline
\end{tabular}

Sumber: Hasil Pengolahan Data, 2019

Kontribusi pekerjaan usaha warung sebesar Rp1.500.000 (37,50\%) dengan total pendapatan sebesar Rp4,000,000, sehingga pekerjaan sambilan selain sebagai nelayan dapat memberikan kontribusi terhadap pendapatan dalam kehidupan perekonomiaan keluarga nelayan dalam rangka menjalani roda kehidupan sehari-hari sedangkan pendapatan yang diperoleh dari usaha warung sebagai pelengkap kebutuhan sehari-hari keluarga nelayan pancing ulur di Kecamatan Mandolang dan usaha warung ini menjadikan sumber dana keluarga untuk ditabung atau berinvestasi misalnya untuk memperbesar warung tersebut.

Kristina (2012) menyebutkan bahwa kontribusi pekerjaan sampingan dari nelayan di desa tambak, yaitu pekerjaan sebagai petani $(48,31 \%)$ jasa $(44,14 \%)$ pedagang beras $(43,83 \%)$ dan sebagai buruh $(41,22)$ peternak $(23,62 \%)$. Pendapatan dan hasil kerja sampingan dipengaruhi oleh factor-faktor: umur, tingkat pendidikan, jumlah keluarga dan jumlah jasa kerja sampingan hal ini juga berlaku pada nelayan di Tateli Weru, dimana faktor-faktor tersebut memang mempengaruhi pendapatan sampingan yang dimaksud. Dibandingkan dengan pendapatan nelayan di Sulut $\mathrm{Rp}$. 8.405.000/tahun memang agak kecil tapi mereka merasa cukup.

\section{KESIMPULAN}

Kontribusi pekerjaan sambilan terhadap pendapatan nelayan pancing ulur tidak lebih besar dari pekerjaan utama, kontribusi pekerjaan sambilan bisa dilihat dapat cukup membantu keluarga nelayan dalam memenuhi kebutuhan sehari-hari.

Besarnya kontribusi pekerjaan sambilan terhadap pendapatan nelayan pancing ulur baik buruh tani $(47.68 \%)$, buruh bangunan $(40.81 \%)$, tukang ojek (32.81\%), dan usaha warung (37.50\%), tidak lebih dari separuh total keseluruhan pendapatan nelayan

\section{DAFTAR PUSTAKA}

Ali, J. et al. 2017. The Contribution of Subsidies on the Welfare of Fishing Communities in Malaysia. International Journal of Economics and Financial Issues, 2017, 7(2), 641-648. 
Dhani, D. 2010. Faktor-Faktor Penyebab Kemiskinan pada Rumah Tangga Nelayan. Skripsi. Bandarlampung: Universitas Lampung.

Fathoni, 2006. Metodologi Penelitian dan Teknik Penyusunan Skripsi. Rineka Cipta. Jakarta.

Imron, M. 2003. Kemiskinan dalam Masyarakat Nelayan. Dalam Jurnal Masyarakat dan Budaya. PMB-LIPI.

Kristina, S. 2012. Analisis Perikanan Ekonomi Nelayan dan Faktor-faktor Yang Mempengaruhi Pendapatan Sampingan RTN di Desa Tambak Raja Kecamatan Brawijaya.

Kurniawan, A. 2009. Belajar Mudah SPPS Untuk Pemula. Yogyakarta penerbit: Mediakom.

Kurniawan, P. 2009. Potret Nelayan Tradisional Kota. Skripsi. Bandar Lampung: Universitas Lampung.

Kusnadi 2002. Konflik Sosial Nelayan: Kemiskinan dan Perebutan Sumber Daya Perikanan. Yogyakarta: LKiS.

Kusnadi. 2006. Perempuan Pesisir. Yogyakarta: LKiS.

Kusnadi, 2008. Akar Kemiskinan Nelayan. Yogyakarta: LKiS.

Laloan, B.F, dkk. 2018. Distribusi Pendapatan Antar Daerah Di Provinsi Sulawesi Utara Vol.14 No 2

Maipita, Indra. 2013. Memahami Konsep Kemiskinan. Http://www.waspada.co.id. Diakses pada tanggal 27 Maret 2019.

Mangkoesoebroto, Guritno. 2000. Ekonomi Publik. Yogyakarta: BPFE.

Manoppo, V. 2013. Mobilitas dan Alih Status Nelayan Skala Kecil di Provinsi Sulawesi Disertasi Pascasarjana IPB. Bogor.

Moleong, Lexy J. 2009. Metode Penelitian Kualitatif. Bandung: Remaja Rosdakarya.

Muchtar. 2014. Menyusun Business Plan \& Rencana Aksi. Cetakan Pertama. Bandung: Yrama Widya.

Purnomo, Heri 2013. Teknik Penetapan Garis Kemiskinan untuk Menghitung Jumlah
Penduduk Miskin. Http://banten.bps.go.id. (Diakses pada tanggal 27 Maret 2019.

Pusat Data, Statistik dan Informasi Kementerian Kelautan dan Perikanan. 2015. Nilai Tukar Nelayan.

Retnowati, E. 2011. Nelayan Indonesia dalam Pusaran Kemiskinan Struktural. (Perspektif Sosial, Ekonomi dan Hukum). Perspektif, Volume XVI, Nomor 3. Surabaya: Universitas Wijaya Kusuma.

Rochana, E. 2011. Survival Strategi Perempuan dalam Menghadapi Gelombang Pasang. Jurnal IImiah Administrasi Publik dan Pembangunan, Volume 2, Nomor 2. Bandar Lampung: Universitas Lampung.

Sekaran, U. 2011. Metode Penelitian Untuk Bisnis. Jakarta: Salemba Empat.

Setia, R. 2005. Gali Tutup Lubang Itu Biasa: Strategi Buruh Menanggulangi Persoalan dari Waktu ke Waktu. Bandung: Yayasan Akatiga.

Sugiyono. 2009. Metode Penelitian Kuantitatif, Kualitatif dan R\&D. Bandung: Alfabeta.

Tain, A. 2011. Penyebab Kemiskinan Rumahtangga Nelayan di WilayahTangkap Lebih Jawa Timur. HUMANITY, Volume 7, Nomor 1. Malang: Universitas Muhammadiyah.

Undang-Undang Nomor 45 Tahun 2009. Tentang Perubahan atas Undang-Undang Nomor 31 Tahun 2004 tentang Perikanan.

Widodo, Slamet. 2011. Strategi Nafkah Berkelanjutan bagi Rumahtangga Miskin di Daerah Pesisir. MAKARA. Volume 15, Nomor 1. Jakarta: Universitas Indonesia.

Wisdaningtyas, Karunia. 2011. Strategi Bertahan Hidup Masyarakat Nelayan di Daerah Pencemaran Pesisir. Skripsi. Bogor: Institut Pertanian Bogor.

Kabupaten Rokan Hilir Provinsi Riau. Jurnal PERIKANAN dan KELAUTAN, Volume 14, Nomor 1. 